\title{
Dengue infection profile in Gujarat, West India: A recent report
}

\author{
Nishita S. Naik ${ }^{1}$, Shiva V. Murarka ${ }^{1}$, Dhariya Sanghrajka ${ }^{1}$, Bhavini S. Shah ${ }^{1}$, Rutvik J. Raval ${ }^{1}$, Mandava V. Rao ${ }^{2 *}$ \\ ${ }^{1}$ Department of Molecular Genetics, Neuberg-Supratech Reference Laboratory, Ahmedabad, India. \\ ${ }^{2}$ Ex-Director, School of Sciences, Gujarat University, Ahmedabad, India.
}

\begin{tabular}{l}
\hline ARTICLE INFO \\
\hline Article history: \\
Received on: March 19, 2019 \\
Accepted on: April 13, 2020 \\
Available online: September 01,2021
\end{tabular}

Key words:

Dengue fever, PCR detection, distribution, biochemical profile and cell counts

\begin{abstract}
Dengue fever (DF) is a mosquito-borne viral disease occurring in tropical and subtropical areas including India. It is manifested by symptoms like fever, headache, rashes, muscle, and joint pains. In our country, Gujarat is one of the highest infected states by this disease due to mosquito bites. Blood samples from such cases were collected and assessed for blood counts, serum transaminases, and blood smears from only positive patients using standard protocols. Real-time PCR (RT-PCR) technique was also employed for virus detection. Of 1020 referral cases, from Ahmedabad, Vadodara, Jamnagar, and Anand districts, 184 cases were detected positive (18.03\%) from October 2016 to December 2019 (39 months) being highest in 2019. Males had a high frequency $(52 \%)$ of infection when compared to females (48\%), affecting young age groups ranging from moderate to higher level. Furthermore, Ahmedabad district (57\%) had a high percentage of infection, compared to others. Marked alterations were also observed with respect to serum glutamate-pyruvate transaminase and serum glutamic oxaloacetic transaminase, platelets, lymphocytes, and WBC counts in positive cases of 0-20, 21-40, and 40-50 year age groups. Reduced platelet clumping and severe thrombocytopenia (59\%) in these cases are early diagnostic markers of dengue, supporting RT-PCR method. Thus from our study, we conclude that dengue infection is caused by various factors such as sex, climate, population, and environment. This outbreak is hence controlled by following health measures strictly, imposed by health departments in Gujarat, Western India.
\end{abstract}

\section{INTRODUCTION}

Dengue is a severe, flu-like illness that affects infants, young children, and adults but sometimes cause deaths. This fever is caused by the Aedes aegypti mosquito bite and is manifested by four dengue viruses occurring in tropical and subtropical areas of the world including India. Its severity ranges from dengue fever (DF) and dengue hemorrhages fever (DHF) to dengue shock syndrome (DSS) in India and around the globe [1-5]. Each one has its own unique manifestation depending on its interaction with the host's response [4-8].

It is a major global public health concern, as more than 2.5 billion people are estimated with this infection [3,9] and more than $50 \times$ $10^{6}$ new cases are being projected annually $[4,10]$. Recently, the National Vector Borne Disease Control Program projected that

\footnotetext{
*Corresponding Author

Mandava V. Rao, Ex-Director, School of Sciences, Gujarat University, Ahmedabad, India.E-mail: manvrao@gmail.com
}

dengue-infected cases are topped in Gujarat in comparison to Karnataka [11], although other states and union territories showed marginal increments till 2019 and then exhibited a decline in dengue cases due to probable increased controlling measures and better sanitization facilities in India.

Outbreaks and deaths due to this have been recorded in the last decade from the Northern states of Haryana, Punjab, and Uttar Pradesh, Southern states of Andhra Pradesh, Tamil Nadu, Kerala, and Karnataka, Western parts of Gujarat and Rajasthan, as well as the Eastern states like West Bengal $[3,4]$. In Gujarat, as percentage of dengue cases increases continuously; this work has been undertaken to investigate this outbreak in four districts, namely Ahmedabad, Baroda, Jamnagar, and Anand. Since more cases get referred to our center of Neuberg-Supratech Reference Laboratory and Research Institute, Ahmedabad, from 2016 to 2019 (39 months) their frequency was calculated to assess controlling measures adopted by respective authorities, and other causative factors in Gujarat, Western India. 


\section{MATERIALS AND METHODS}

\subsection{Patients' Selection}

Patients (1020) suspected for DF based on clinical reports and exposed to mosquito bites from four district centers were referred to our main center, i.e., Neuberg-Supratech Reference Laboratory and Research Institute, Ahmedabad. These referral cases were divided into four age groups: $0-20,21-40,41-50$, and 51 and above from October 2016 to December 2019 (39 months). Each patient was asked to fill out a concern form, followed by blood collection on priority basis. Then, analysis was carried out after approval of our ethical committee for investigation (GU/HEC001-2015) Ahmedabad, in 2015.

\subsection{Hematological and Biochemical Profiles}

Complete blood cell count was carried out using cell counter (Siemen's Advair 2010, Germany). Serum transaminases of serum glutamic oxaloacetic transaminase (SGOT)/aspartate transaminase and serum glutamate-pyruvate transaminase (SGPT)/alanine transaminase were estimated using a kit (Dimension EXL, Germany), which was expressed as U/1. Blood smear for positive cases was prepared using Leishman stain and the peripheral blood film was observed under the microscope for morphology of blood cell types like lymphocytes, neutrophils, RBC, and platelets under the light microscope from lower to higher magnification [12]. The report on these cell types was assessed by pathologists in our laboratory.

\subsection{Dengue Viral Detection}

The real-time PCR (RT-PCR) assay used in this study for the detection of the dengue virus was TaqMan's primer and probe mixer by in-house method. The assay allowed for a qualitative detection of dengue virus-specific RNA, with reverse-transcription of the RNA into complementary DNA, followed by PCR for the amplification of specific target sequences. The probes utilized were specific for DENV RNA labeled with the fluorophore FAMTM and specific for the internal control labeled with the fluorophore VICTM. The in-house protocol used QuantStudio5 instrument for $\mathrm{Ab}$ detection. The data obtained were entered into the Microsoft Excel spread sheet and descriptive statistics were carried out to obtain $\mathrm{C}$ analysis of variance. $p$-value less than 0.05 was considered significant.

\section{RESULTS}

Of 1,020 referral cases, 184 cases were positive for DF (184/1,020 $=18.03 \%$ ). During 39 months of our study, Jan-Dec 2019 had the highest frequency of cases $(54 / 259=20.84 \%)$, followed by JanDec $2018(63 / 326=19.32 \%)($ Table 1$)$. The young age group $(0$ $20 ; 21-40$ years) possessed a higher percentage of cases in both sexes. However, males (52\%) had a high percentage of affected cases in comparison to females (48\%) in our report (Table 2).

\subsection{Biochemical and Hematological Profile}

The levels of SGPT and SGOT had a higher percentage than normal levels in all age groups. However, this trend had declined
Table 1: Year-wise prevalence of dengue cases referred in Oct 2016-Dec 2019 (39 months).

\begin{tabular}{cccc} 
Year & \multicolumn{3}{c}{ Dengue } \\
& Total & Positive & Percentage \\
\hline Oct-Dec 2016 & 150 & 24 & 16.00 \\
Jan-Dec 2017 & 285 & 43 & 15.08 \\
Jan-Dec 2018 & 326 & 63 & 19.32 \\
Jan-Dec 2019 & 259 & 54 & 20.84 \\
Total & 1,020 & 184 & 18.03 \\
\hline
\end{tabular}

with increased age (Table 3). The platelets count was reduced in all positive cases, compared to negative cases. It was significant $(p<0.0170)$ in the $21-40$ years age group. Similarly, WBC counts significantly $(p>0.0004, p>0.0003$, and $p>0.0262)$ reduced in three young age groups of positive cases, respectively. The same trend was found with respect to lymphocytes $(p<0.0001$ and $p$ $<0.0210$ ) in all age groups (Table 4). Among the four districts of Gujarat, Ahmedabad topped (57\%) the cases, followed by Vadodara (17\%), Jamnagar (16\%), and Anand (10\%) respectively (Fig. 1).

\subsection{Blood Cell Morphology}

Blood films were done for all positive cases (184) and cell abnormalities were observed by the pathologists. RBC had nucleated $(27 \% ; 50 / 184)$ and hypochromic and neutrophil exhibited fragmentation $(42 / 184 ; 23 \%)$, whereas lymphocytes became atypical, as shown in Figure $2(68 / 184 ; 37 \%)$. Platelets in some peripheral blood films contained no agglutination/clumping with thrombocytopenia $(109 / 184 ; 59 \%)$, which are markers for dengue infection (Fig. 3).

\section{DISCUSSION}

Dengue is the most extensively spread mosquito-borne disease, endemic in more than 100 countries around the globe. Its burden, prevalence, incidence, and distribution in Gujarat is necessary, as it shows an increasing trend [5,11]. The study carried out by us depicted a sharp rise in positive samples from year 2017 to 2019 , in support of earlier data presented $[11,13,14]$. The frequencies of infected cases also were higher in months corresponding to monsoon season $[3,4,15]$.

In general, all age groups are affected by DF in India $[12,16,17]$. Younger age groups are more commonly infected by DF in support of our data where the 21-40 years age group is has both sexes infected. Dinkar and Singh [15] reported that the 20-30 age group is more infected as found during the epidemic in Delhi and other states like Chandigarh, Haryana, Maharashtra, Punjab, and UP. Predominantly children and adults of these age groups are active, who were out of the house most of the time either playing or at work [18-21]. But on the other hand, few reports recorded a higher rate of cases in the 5-12 age group due to lack of immunity [2].

This study also found that males are maximally affected by DF than females. Similarly, most of the reports found that a high male to female ratio was shown in most of the outbreaks in India 
Table 2: Age and gender-wise percentage (\%) of positive dengue cases (184) in the study (Oct 2016-Dec 2019).

\begin{tabular}{ccccccc} 
Age group & \multicolumn{2}{c}{ Male } & \multicolumn{2}{c}{ Female } & \multicolumn{2}{c}{ Total patients } \\
$0-20$ & Positive & Percentage & Positive & Percentage & Positive & Percentage \\
$21-40$ & 36 & 38 & 26 & 29 & 62 & 33.69 \\
$41-50$ & 40 & 42 & 35 & 40 & 75 & 40.76 \\
51 above & 04 & 4.2 & 14 & 16 & 18 & 09.78 \\
Total & 16 & 16 & 13 & 15 & 29 & 15.76 \\
\hline
\end{tabular}

Table 3. Percentage (\%) of serum transaminase level in dengue cases (184) (Oct 2016Dec 2019) in the four age groups.

\begin{tabular}{ccc} 
Age group & SGPT (100\%) (U/I) & SGOT (100\%) (U/I) \\
$0-20$ & $60.33(165.28 \%)$ & $57.92(156.54 \%)$ \\
$21-40$ & $57.88(158.57 \%)$ & $72.02(194.64 \%)$ \\
$41-50$ & $72.01(197.28 \%)$ & $67.02(181.13 \%)$ \\
51 above & $51.14(140.93 \%)$ & $40.66(109.89 \%)$ \\
\hline
\end{tabular}

Normal range - SGPT: 14-59 U/1; SGOT: 0-37 U/1.

Table 4: Blood cell count in dengue-positive cases versus negative cases (Oct 2016-Dec 2019) in our study.

\begin{tabular}{lccccc} 
Blood cell type & Case type & \multicolumn{4}{c}{ Age groups in years } \\
& & $\mathbf{0 - 2 0}$ & $\mathbf{2 1 - 4 0}$ & $\mathbf{4 1 - 5 0}$ & $\mathbf{5 1}$ above \\
Platelets count & Negative & $257,173 \pm 118,405$ & $226,385 \pm 98,188$ & $218,157 \pm 83,346$ & $208,445 \pm 91,767$ \\
$(150,000-410,000) /$ & Positive & $217,705 \pm 96,935$ & $185,033 \pm 68,727^{*}$ & $191,000 \pm 48,862$ & $174,718 \pm 55,447$ \\
$\mu 1$ & $p$ value & 0.1723 & 0.0170 & 0.3112 & 0.1439 \\
RBC $(3.8-4.8$ & Negative & $4.85 \pm 0.85$ & $4.62 \pm 0.50$ & $5.34 \pm 5.62$ & $4.58 \pm 1.41$ \\
Million/Cumm) & Positive & $5.01 \pm 0.51$ & $4.49 \pm 0.69$ & $4.52 \pm 0.69$ & $4.31 \pm 0.70$ \\
& $p$ value & 0.4158 & 0.2164 & 0.6493 & 0.4412 \\
WBC $(4,000-$ & Negative & $7,599 \pm 3,780$ & $6,100 \pm 2,875$ & $5,985 \pm 2,611$ & $6,571 \pm 3,268$ \\
$10,000) / \mu 1$ & Positive & $4,405 \pm 2,171^{+}$ & $4,214 \pm 2,052^{++}$ & $4,012 \pm 1,594^{+++}$ & $5,501 \pm 2,133$ \\
& $p$ value & 0.0004 & 0.0003 & 0.0262 & 0.1947 \\
Lymphocytes count & Negative & $1,912 \pm 1,094$ & $1,291 \pm 783$ & $1,147 \pm 693$ & $1,377 \pm 1,259$ \\
$(1,000-3,000) / \mu 1$ & Positive & $929 \pm 411 @$ & $768 \pm 347 @$ & $613 \pm 267$ & $913 \pm 657$ \\
& $p$ value & 0.0001 & 0.0001 & 0.0210 & 0.1410 \\
Hb $(12.0-15.0 \mathrm{G} \%)$ & Negative & $13 \pm 2.19$ & $13.1 \pm 1.76$ & $12.6 \pm 2.24$ & $13.44 \pm 8.52$ \\
& Positive & $13.81 \pm 1.58$ & $12.89 \pm 2.12$ & $12.88 \pm 0.85$ & $12.40 \pm 1.86$ \\
& $p$ value & 0.1213 & 0.5494 & 0.7030 & 0.6181 \\
\hline
\end{tabular}

Values are Mean $\pm \mathrm{SE}$; Figures in parentheses indicate normal range.

$[3,4,15,22,23]$. The difference in gender may be due to social and cultural biasing with male predominance. Male partners are more exposed to various environmental factors in tropical and subtropical areas and are more prone to getting infection $[3,24,25]$.

A regional study of Gujarat screened in the four districts showed Ahmedabad had a higher frequency of the dengue virus, compared to Varodara, Jamnagar, and Anand. This could be due to migration of population for better survival, poor sanitization facilities, and seasonal variants for the vectors, A. aegypti and Ae. albopictus and environmental conditions [1,2,26,27]. The data were supported by drastic increase in serum aminases in our study. This increase in SGPT and SGOT levels is correlated to liver dysfunction due to DF. Other biochemical profiles like serum protein, albumin, and urea levels also altered dengue infection to separate Chikungunya [6] in addition to higher hematocrit, tachycardia, cough, and fever in dengue cases to boost our results [4].

Hematological profile exhibited significantly reduced platelet count, followed by WBC in dengue patients in collaboration with the data of others $[4,6,26]$. Increased thrombocytopenia and lack of platelet clumping in our present study also challenged the condition of dengue. Decrease in lymphocytes and other WBC counts indicated loss of immune and other functions in these positive cases comparable to negative patients in our study $[6,27,28]$. In patients with dengue, atypical lymphocytes were noticed and boost the loss of their immune status. Neutrophils were fragmented in some of the patients' blood smear as reported 


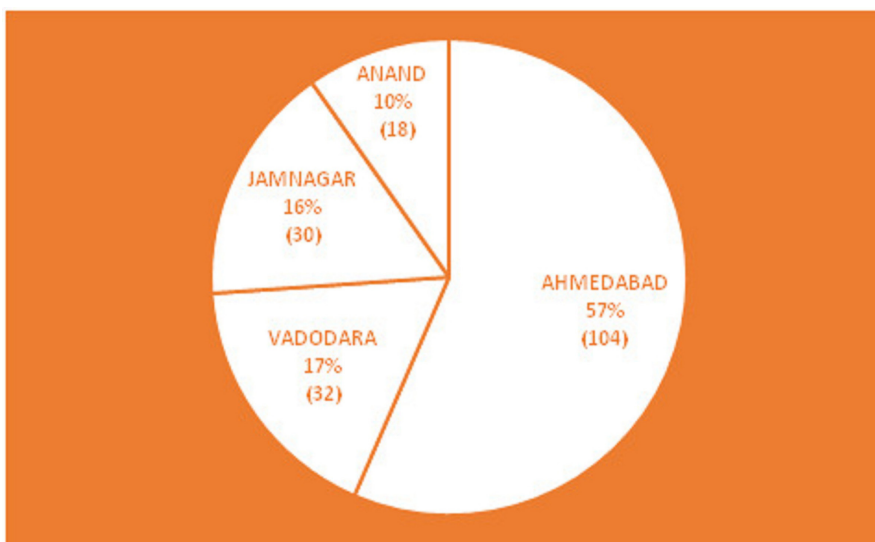

Figure 1: Distribution of dengue positive cases (184) within the four districts of Gujarat (Oct 2016-Dec 2019).

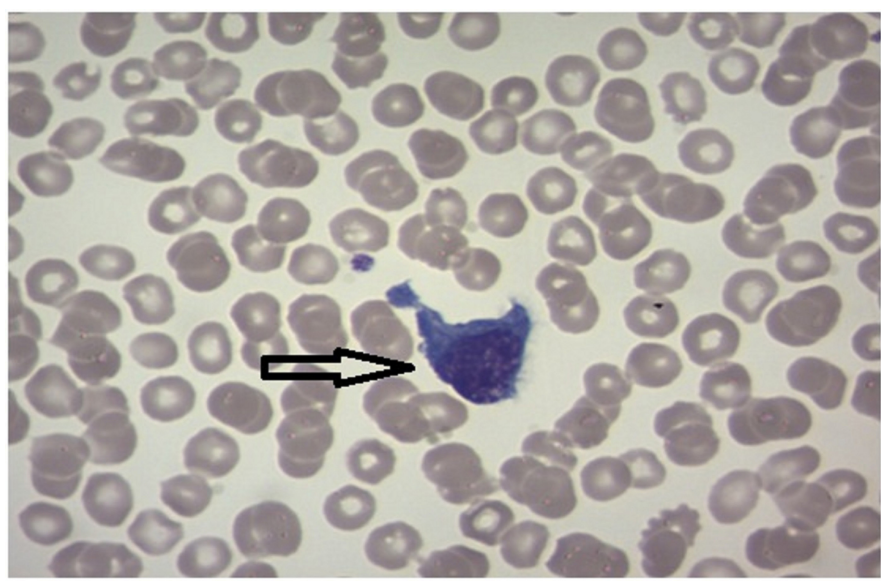

Figure 2: Atypical lymphocytes $(\rightarrow)$ observed in blood smear of dengue positive patients.

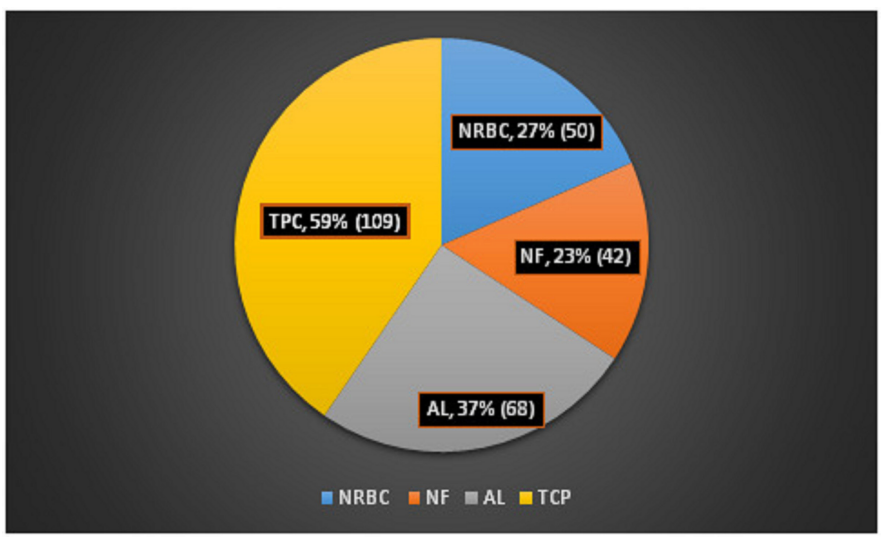

Figure 3: Abnormal blood cell type in positive cases (184). NRBC $=$ Nucleated $\mathrm{RBC} ; \mathrm{NF}=$ Neutrophil Fragmentation; $\mathrm{AL}=$ Atypical Lymphocytes; $\mathrm{TCP}=$ Thrombocytopenia.

by our pathologists. Few blood smear films exhibited nucleated RBC (NRBC) and hypochromic cells. All these abnormalities of blood cells presented bone marrow cell differentiation arrest or irregularity, display of hypocellularity probably by dengue virus, and its antigen interplay with progenitor cells [12]. Some researchers $[12,27]$ extensively worked on morphological features of blood cells in dengue-infected patients as well as other viral infection, and they proposed that the presence of thrombocytopenia and atypical lymphocytes are an important diagnostic clues for exact early and alternative diagnosis for dengue infection to support of our study, although molecular detection method (RTPCR) is to be a gold standard technique for it at present. Thus, our study cohort revealed that dengue disease prevailed in Gujarat and continued to be high till 2019 and depended on region, season, age, gender and other environmental conditions as suggested by others [29-31].

\section{CONCLUSION}

The data of our study clearly demonstrated that dengue infection is caused by mosquito bites affecting the humans. A careful study of dengue virus is mapped to understand the spread of DF, DHF, and DSS. In Gujarat, its prevalence, incidence, and epidemiology is quite high from 2016 to 2019 (39 months) due to several factors. With a total of 184 cases, infections were high in the younger age group, males, and Ahmedabad district. This viral disease is supported by increased transaminases, alterations in $\mathrm{WBC}$, and platelets. Morphological features of blood cells highlighted the early dengue symptoms as evidenced by thrombocytopenia, platelet clumping, and atypical lymphocytes in addition to PCR, which is standard. Hence, Gujarat in Western India should follow the proper recommendations of the World Health Organizations [26], otherwise it will play havoc, if immediate control measures are not taken.

\section{RECOMMENDATION}

This cohort suggests an urgent need to check DF and much care needs to be made available by the health departments to eradicate breeding sites of mosquitoes, vaccination facilities, if any, as well as provide clear environment to the public in future, following stratification of healthcare policies strictly around the globe including India. There is also an urgent need for a long-term vector control strategy to prevent this outbreak.

\section{ACKNOWLEDGMENT}

The authors are thankful to the staff of all our centers in Gujarat for their support and help.

\section{CONFLICT OF INTEREST}

The authors express no conflicts of interests regarding this manuscript.

\section{FUNDING}

There is no funding to report.

\section{REFERENCES}

1. Kathiriya A, Shah NM, Patel JS, Javia BB, Tajpara MM, Qhodasara $\mathrm{SN}$, et al. Epidemiological surveillance of Dengue fever. An overview. Int J Vet Sci Amin Hasb 2020;5(6):1-10. 
2. Gupta N, Srivastava S, Jain A, Chaturvedi UC, Dengue in India. Indian J Med Res 2012;136:373-90.

3. Mehta KD, Gelotar PS, Vachhani SC, Makwana N, Sinha M. Profile of Dengue infection in Jamnagar city and District, West India. WHO South East Asia J Public Health 2014;3:72-4.

4. Shah PS, Shah ND, Patel AS, Kartadikar SM, Dixit HD, Patel KR, et al. Dengue and viral circulation in infected cases of Ahmedabad: a single centre study. Ethno Med, 2017;11(4):297-301.

5. WHO. Dengue and savior Dengue. World Health Organization, Geneva, Switzerland, 2020. Available via https://www.who.int/newsroom/fact-sheets/detail/dengue-and-severe-dengue (Accessed April 2021).

6. Lee V, Chow A, Zheng X, Carrasco L, Cook A, et al. Simple clinical and laboratory prediction of Chikungunya vs. Dengue infection in adults. PLoS Negl Trop Dis, 2012;6(9):e1786.

7. Islam A, Abdullah M, Tazeen A, Afreen N, Deeba F, Naqvi IH. Detection of all the four serotypes of dengue virus in New Delhi, India during post monsoon season of 2015. Indian J Health Sci Care 2016;3(3):24-9.

8. Garg S, Chakravarti A, Singh R, Masthi NR, Goyal RC, Jammy GR, et al. Dengue serotype-specific seroprevalence among 5-to 10-yearold children in India: a community-based cross-sectional study. Int J Infect Dis 2017;54:25-10.

9. Halstead S. Recent advances in understanding dengue. F1000Res 2019;8:F1000; doi:10.12688/f1000research.19197.1

10. Cecilia D. Current status of dengue and chikungunya in India. WHO South East Asia J Public Health, 2014;3:1.

11. NUBDCP. National Vector Borne Diseases Control Program on Dengue cases and deaths in the country since. NUBDCP, 2015. Available via https://nvbdcp.gov.in/index4. php?lang $=1 \&$ level $=0 \&$ linkid $=437 \&$ lid $=3715 \quad$ (Accessed January 2021).

12. Yunus YM, Narowi M, Lai HI. Morphological features analysis in pathogenic Dengue infection as an alternative screening method. Int J Acad Res Bus Soc Sci 2017;7:801-11.

13. World Health Organization. Global strategy for dengue prevention and control 2012-2020. World Health Organization, Geneva, Switzerland, 2012.

14. Ganeshkumar P, Murhekar MV, Poornima V, Saravanakumar V, Sukumaran K, Anandaselvasankar A, et al. Dengue infection in India: a systematic review and meta-analysis. PLoS Negl Trop Dis 2018;12(7):1-29.

15. Dinkar A, Singh J. Dengue infection in North India: an experience of a tertiary care center from 2012 to 2017. Tzu-Chi Med J 2020;32(1):3640.

16. Singh J, Dinkar A, Atam V, Misra R, Kumar S, Gupta KK, et al. Intracranial hemorrhage in dengue fever: a case series. J Med Sci Clin Res 2015;3:4447-52.

17. Murhekar MV, Kamaraj P, Kumar MS, Khan SA, Allam RR, Barde $\mathrm{P}$, et al. Burden of dengue infection in India, 2017: a cross-sectional population based serosurvey. Lancet Glob Health 2019;7(8):e106573; doi:10.1016/S2214-109X(19)30250-5

18. Chakravarti A, Arora R, Luxemburger C. Fifty years of dengue in India. Trans R Soc Trop Med Hyg 2012;106:273-82.
19. Singh J, Dinkar A, Singh RG, Siddiqui MS, Sinha N, Singh SK. Clinical profile of dengue fever and confection with chikungunya. Tzu-Chi Med J 2018:30:158-64.

20. Kumar A, Rao CR, Pandit V, Shetty S, Bammigatti C, Samarasinghe CM. Clinical manifestations and trend of dengue cases admitted in a tertiary care hospital, Udupi district, Karnataka. Indian J Community Med 2010;35:386-90.

21. Kumar M, Verma RK, Mishra B. Prevalence of dengue fever in Western Uttar Pradesh, India: a gender-based study. Int J Appl Basic Med Res 2021;10:8-11.

22. Sinha N, Gupta N, Jhamb R, Gulati S. The 2006 dengue outbreak in Delhi, India. J Commun Dis 2008;40:243-8.

23. Patankar M, Patel B, Gandhi V, Shah P, Vegad M. Seroprevalence of Dengue in Gujarat, Western India: a study at a tertiary care hospital. Int J Med Sci Public Health 2014;3(1):16-18.

24. Paramasivan R, Thenmozhi V, Hiriyan J, Dhananjeyan KJ, Tyagi BK, Dash AP. Serological \& entomological investigations of an outbreak of dengue fever in certain rural areas of Kanyakumari district, Tamil Nadu. Indian J Med Res 2006;123:697-701.

25. Bhattacharjee N, Mukherjee KK, Chakravarti SK, Mukherjee MK, De PN, Sengupta M, Chakraborty MS. Dengue haemorrhagic fever (DHF) outbreak in Calcutta-1990. J Commun Dis 1993;25:10-4.

26. World Health Organization. Dengue: guidelines for diagnosis, treatment, prevention and control. World Health Organization, Geneva, Switzerland, 2009.

27. Mehta RC, Goswami HM, Katara RK, Patel PS, Parikh UV, Vegad $\mathrm{MM}$, et al. Importance of complete blood count and peripheral smear examination in early diagnosis of dengue patients. J Infect Dis Lett 2013;2(1):22-4.

28. Jones KW. Evaluation of cell morphology and introduction to platelet and white blood cell morphology. Clin Hematol Fundam Hemost 2009;93-116.

29. Zhang Y, Ibaraki M, Schwartz FW. Disease surveillance using online news: an extended study of dengue fever in India. Trop Med Health 2019;47:58-69.

30. Shet A, Kang G. Dengue in India: towards a better understanding of priorities and progress. Int J Infect Dis 2019;84:S1-3.

31. Wang WH, Urbina AN, Chang MR, Assavalapsakul W, Lu PL, Chen $\mathrm{YH}$, et al. Dengue hemorrhagic fever-a systemic literature review of current perspectives on pathogenesis, prevention and control. J Microbiol Immunol Infect 2020;53(6):963-78.

How to cite this article:

Naik NS, Murarka SV, Sanghrajka D, Shah BS, Raval RJ, Rao MV. Dengue infection profile in Gujarat, West India: A recent report. J Appl Biol Biotech 2021; 9(05):96-100. 